\title{
RESULTS OF HOLTER MONITORING IN PATIENTS WITH CORONARY HEART DISEASE DEPENDING ON THE SEVERITY OF ATHEROSCLEROTIC LESIONS OF THE CORONARY ARTERIES
}

\author{
Tetiana Pylova
}

The aim - to conduct a comparative analysis of the presence, frequency and duration of episodes of myocardial ischemia and arrhythmias based on the results of Holter monitoring in patients with coronary heart disease depending on the condition of the coronary arteries.

Materials and methods. We examined 53 patients (group I) with stable coronary heart disease (CHD) and slightly altered coronary arteries (INOCA), who were hospitalized in the period from October 2018 to February 2021 at the "City Clinical Hospital No. 8" of Kharkiv City Council. Group II included 52 patients with a diagnosis of stable coronary heart disease, and according to coronary angiography (CAG) had stenosis of coronary arteries (CA) more than $50 \%$.

Results. According to the results of comparative analysis, it was found that in group I there were signs of myocardial ischemia - depression of the ST segment in $62.3 \%(n=33)$ and elevation of the ST segment in $11.3 \%(n=6)$, compared with group II - $73 \%(n=38)$ and $5.66 \%(n=3)$, respectively. Ventricular arrhythmias (VA) have been reported in 52 patients of group I, and in 44 patients of group II. VA 4 and 5 type according to Laun, was significantly higher in group II compared with group I $(p=0.0324)$. The occurrence of ventricular tachycardia was recorded in $5.7 \%(n=3)$ of patients in group I and $9.3 \%(n=5)$ patients of group II $(p=0.347)$. In group II, there was a tendency to more episodes of ischemia compared with group I $(p=0.072)$. The duration of ischemia was significantly longer in group I, compared with group II $(p=0.042)$.

Conclusions. The results of the study did not show significant differences in the development of the number of episodes of myocardial ischemia according to Holter monitoring depending on the condition of the coronary arteries. The duration of episodes of ischemia in patients with INOCA is significantly longer than in patients with obstructive atherosclerosis. In patients with coronary heart disease with obstructive coronary arteries, ventricular arrhythmia was statistically significantly more severe according to Lown

Keywords: Holter ECG monitoring, coronary heart disease with altered coronary arteries, chronic coronary syndrome, INOCA

How to cite:

Pylova, T. (2021). Results of holter monitoring in patients with coronary heart disease depending on the severity of atherosclerotic lesions of the coronary arteries. ScienceRise: Medical Science, 3 (42), 15-19. doi: http://doi.org/10.15587/2519-4798.2021.232642

(C) The Author(s) 2021

This is an open access article under the Creative Commons CC BY license

\section{Introduction}

Tests with dosed exercise are the gold standard for detecting coronary heart disease [1]. However, a number of patients are unable to perform the required level of exercise to confirm the diagnosis of coronary heart disease, which complicates the diagnosis of myocardial ischemia. Although the severity level of ischemia detected in non-invasive stress tests is prognostic in patients with stable coronary heart disease. It is important to understand that a normal stress test does not rule out vasomotor dysfunction as a cause of angina in patients with minor lesion of the coronary arteries (INOCA) [2]. Therefore, the sensitivity of this test in such patients is also lower, compared with daily electrocardiogram (ECG) monitoring. Holter electrocardiogram monitoring is a simple, but at the same time very informative noninvasive method of diagnosing coronary heart disease and arrhythmias in patients with cardiovascular pathology, which provides ECG recording in normal daily ac- tivity of the patient $[3,4]$. Therefore, it is especially important to conduct Holter monitoring in patients with INOCA [5]. Unfortunately, there is insufficient information in the modern literature on the results of Holter monitoring in patients with no obstructive coronary arteries disease (CAD) [6].

The aim of the work is to conduct a comparative analysis of the presence, frequency and duration of episodes of ischemia and arrhythmias according to the results of Holter monitoring in patients with coronary heart disease depending on the condition of the coronary arteries.

\section{Materials and methods}

1060 angiographies of patients with a diagnosis of stable coronary heart disease who were hospitalized in the period from October 2018 to February 2021 to the "City Clinical Hospital No. 8" of the Kharkiv City Council were analyzed. The criteria for the diagnosis of INOCA present in $n=53(5 \%)$ of patients who were includ- 
ed for further study and formed group I. Group II consisted of $n=52$ patients diagnosed with coronary heart disease, who were hospitalized from June to December 2020, and according to CAG had stenosis of more than $50 \%$. CHD was diagnosed on the basis of classic clinical manifestations of angina [6], reliable data of myocardial ischemia according to Holter ECG monitoring in the form of depression/elevation of ST segment (horizontal or descending decrease of ST segment by $0.1 \mathrm{mV}$ at the point, segment elevation ST at $0.1 \mathrm{mV}$ with a duration of $80 \mathrm{~ms}$ from point $\mathrm{J}$ ), as well as the presence of a history of verified myocardial infarction [7, 8].

The work was approved by the Bioethics Committee of Kharkiv Medical Academy of Post-graduate Education (Report No. 1 of $11^{\text {th }}$ February 2021) in accordance with the Code of Ethics of the World Medical As- sociation (Helsinki Declaration). All patients included in study provided written inform consent.

Exclusion criteria: severe comorbidities (valve defects, cancer, chronic kidney disease (CKD) above stage II, severe type 2 diabetes mellitus (DM2), etc.), acute coronary syndrome. Clinical and anamnestic characteristics of patients are shown in Table 1.

All patients underwent general clinical and instrumental research methods in accordance with the standards for the diagnosis of coronary heart disease [9].

CAG was performed mainly by right transradial access, by the method of selective catheterization on the TOSHIBA INFX-8000C (Japan) with software, according to the generally accepted method. The presence of hemodynamically significant stenosis was assessed according to the AHA classification [10].

Table 1

Clinical and anamnestic characteristics of the examined groups of patients

\begin{tabular}{|l|c|c|c|}
\hline \multicolumn{1}{|c|}{ Parameters } & Group I $(\mathrm{n}=53)$ & Group II $(\mathrm{n}=52)$ & $\mathrm{p}$ \\
\hline Age, years $(\mathrm{M} \pm \sigma)$ & $56.83 \pm 9.72$ & $60.12 \pm 9.94$ & 0.1151 \\
\hline Women, $\mathrm{n}(\%)$ & $35 / 66.0$ & $17 / 32.7$ & 0.0006 \\
\hline Men, $\mathrm{n}(\%)$ & $18 / 34.0$ & $35 / 67.3$ & 0.0006 \\
\hline Arterial hypertension in anamnesis, $\mathrm{n}(\%)$ & $38 / 71.7$ & $42 / 80.8$ & 0.2752 \\
\hline Diabetes Mellitus, $\mathrm{n}(\%)$ & $8 / 15.1$ & $16 / 30.8$ & 0.0930 \\
\hline Hyperlipidemia ${ }^{1} \mathrm{n}(\%)$ & $31 / 58.5$ & $20 / 38.5$ & 0.0401 \\
\hline Smoking, $\mathrm{n}(\%)$ & $12 / 22.6$ & $15 / 28.8$ & 0.4670 \\
\hline Heredity ${ }^{2} \mathrm{n}(\%)$ & $3 / 5.7$ & $5 / 9.6$ & 0.3471 \\
\hline MI in anamnesis, $\mathrm{n}(\%)$ & $16 / 30.2$ & $31 / 59.9$ & 0.0002 \\
\hline CKD in anamnesis ${ }^{3}, \mathrm{n}(\%)$ & $2 / 3.8$ & 0 & 0.2524 \\
\hline Stroke, $\mathrm{TIA}^{4}, \mathrm{n}(\%)$ & $3 / 5.7$ & $5 / 9.6$ & 0.3471 \\
\hline BMI kg/m ${ }^{5},(\mathrm{M} \pm \sigma)$ & $28.26 \pm 4.00$ & $27.81 \pm 3.38$ & 0.6795 \\
\hline
\end{tabular}

Note: ${ }^{1}$ Hyperlipidemia: $C H D>5.2 \mathrm{mmol} / \mathrm{L}$, and / or LDL cholesterol $>3 \mathrm{mmol} / \mathrm{L}$, and/or TG>1.7 mmol/L. ${ }^{2} \mathrm{Heredity:} \mathrm{family} \mathrm{history}$ of premature cardiovascular disease (men - under 55 years; women - under 60 years). ${ }^{3}$ CKD in the anamnesis: CKD of the III - IV stages (decrease in GFR respectively 30-59 $\mathrm{ml} /\left(\mathrm{min} \bullet 1.73 \mathrm{~m}^{2}\right)$ and $15-29 \mathrm{ml} /\left(\mathrm{min} \bullet 1.73 \mathrm{~m}^{2}\right) .{ }^{4}$ TIA - transient ischemic attacks, ${ }^{5} B M I-$ body mass index

Holter ECG monitoring was performed using a device model 3225 "DIAKARD" (JSC "Solveig", Ukraine). Analysis of ST segment deviations relative to isoline and arrhythmias was performed automatically according to generally accepted criteria. Holter ECG monitoring was used to assess the presence and number of ischemia episodes, the occurrence of arrhythmias, and the number and duration of ischemia.

Classification of premature ventricular contractions (PVCs) according to Lown-Wolf

- I - up to 30 extrasystoles for any hour of monitoring;

- II - more than 30 extrasystoles for any hour of monitoring;

- III - polymorphic extrasystoles;

- IVa - paired extrasystoles;

- IVb - group extrasystoles, triplets and more, ventricular tachycardia (VT);

- V - early ventricular extrasystoles type $\mathrm{R}$ on $\mathrm{T}$.

Statistical data processing was performed using Statistica 8.0 (StatSoft Inc, USA) and Excel 2003. With normal distribution, quantitative characteristics were presented as mean and standard deviation $(\mathrm{M} \pm \sigma)$. Student's test was used to compare the average of the two samples. Intergroup differences in qualitative signs were assessed using Pearson's $\chi 2$ test. For all types of analysis, the differences were statistically significant at $\mathrm{p}<0.05$.

\section{Results}

According to the comparative results of analysis Holter ECG monitoring (Table 2) it was found that in the group with slightly altered coronary arteries (group I) revealed signs of myocardial ischemia in the form of STsegment depression in $62.3 \%(n=33)$ and elevation of the ST-11.3\% segment $(n=6)$, compared with the group with stenotic atherosclerosis (group II) - $73 \%(n=38)$ and $5.66 \%(n=3)$. In group II there was a tendency to more frequent episodes of myocardial ischemia compared with group I $(\mathrm{p}=0.072)$. The duration of ischemia was significantly longer in group I, compared with group II $(\mathrm{p}=0.042)$. Atrial fibrillation was registered in patients of group I in $7 \%$ of cases $(n=4)$, compared with patients in group II $-12 \%(n=7)$. 
Table 2

Holter ECG results depending on the CA damage

\begin{tabular}{|c|c|c|c|}
\hline Parameters & Group I $(n=53)$ & Group II $(n=52)$ & $\mathrm{p}$ \\
\hline Positive stress test & $19 / 35.8$ & $30 / 57.7$ & 0.0249 \\
\hline Average $\mathrm{HB}^{1}$ per minute & $69.88(10.33)$ & $71.96(8.25)$ & 0.368 \\
\hline Circadian index, $(\mathrm{M} \pm \sigma)$ & $1.29 \pm 0.1$ & $1.38 \pm 0.8$ & 0.115 \\
\hline $\mathrm{SVT}^{2},(\mathrm{n}, \%)$ & $15(27.8)$ & $12(23)$ & 0.4670 \\
\hline $\mathrm{SVE}^{3}$ & $169.3[0-2479]$ & $606.5[0-10294]$ & 0.742 \\
\hline SVE, $(n, \%)$ & $29(54.7)$ & $24(46)$ & 0.672 \\
\hline Up to $500,(n, \%)$ & $24(41.37)$ & $16(30.8)$ & 0.091 \\
\hline $500-1000,(\mathrm{n}, \%)$ & $2(3.77)$ & $3(5.76)$ & 0.315 \\
\hline More $1000,(n, \%)$ & $3(5.66)$ & $5(9.6)$ & 0.347 \\
\hline $\mathrm{PVCs}^{4}$ & $642[0-19361]$ & $429[0-8984]$ & 0.231 \\
\hline Up to $500,(n, \%)$ & $30(56 \%)$ & $25(53.8)$ & 0.118 \\
\hline 500-1000, (n, \%) & $14(26.4 \%)$ & $14(26.9 \%)$ & 0.413 \\
\hline More $1000,(\mathrm{n}, \%)$ & $4(7.5 \%)$ & $6(15.4 \%)$ & 0.347 \\
\hline \multicolumn{4}{|l|}{ Type according to Lown } \\
\hline $1,(\mathrm{n}, \%)$ & $29(54.7)$ & $25(38.4)$ & 0.320 \\
\hline $2,(\mathrm{n}, \%)$ & $6(11.3)$ & $22(42.3)$ & 0.062 \\
\hline $3,(\mathrm{n}, \%)$ & $3(5.66)$ & $4(7.69)$ & 0.322 \\
\hline $4 \mathrm{a},(\mathrm{n}, \%)$ & 0 & $3(5.8)$ & 0.413 \\
\hline $4 \mathrm{~b},(\mathrm{n}, \%)$ & $3(5.66)$ & $6(11.5)$ & 0.347 \\
\hline $5,(\mathrm{n}, \%)$ & 0 & $3(5.8)$ & 0.2524 \\
\hline Together $4 \& 5$ type & $3(5.66)$ & $12(23.07)$ & 0.0324 \\
\hline Ventricular tachycardia & $3(5.66)$ & $5(5.76)$ & 0.347 \\
\hline Atrial fibrillation & $4(6.9)$ & $7(12.06)$ & 0.427 \\
\hline Elevation ST & $6(11.3)$ & $3(5.76)$ & 0.312 \\
\hline Depression ST & $33(62.26)$ & $38(73)$ & 0.420 \\
\hline Negative T & $25(46.3)$ & $28(53.8)$ & 0.115 \\
\hline Left and right bundle branch block & $10(18.9)$ & $8(15.3)$ & 0.241 \\
\hline Duration of episodes of ischemia min/day & $20.21 \pm 1.73$ & $3.04 \pm 0.12$ & 0.042 \\
\hline Number of episodes of myocardial ischemia per day & 2.6 & 4.7 & 0.072 \\
\hline
\end{tabular}

Note: ${ }^{I} \mathrm{HB}$ - heart beats, ${ }^{2} \mathrm{SVT}-$ supraventricular tachycardia, ${ }^{3} \mathrm{SVE}$ - supraventricular extrasystole, ${ }^{4} \mathrm{PVCs}$ - premature ventricular contractions.

Supraventricular extrasystolic (SVE) arrhythmia was detected in $29(54.7 \%)$ patients with altered CA (group I), and in 24 (46\%) patients with obstructive CAD. Supraventricular tachycardia (SVT) was reported in $27.8 \%$ (15) of patients in group I, compared with $23 \%$ (12) of patients in group II. In a comparative analy- sis of the number of obtained ventricular extrasystoles, no statistically significant differences between groups were found, in group I PVCs was registered in $48(92.3 \%)$ patients of group I, in $44(86.5 \%)$ patients of group II $(\mathrm{p}=0.231)$ The Fig. 1 illustrates the distribution of patients according to the number of PVCs episodes per day.
Group I

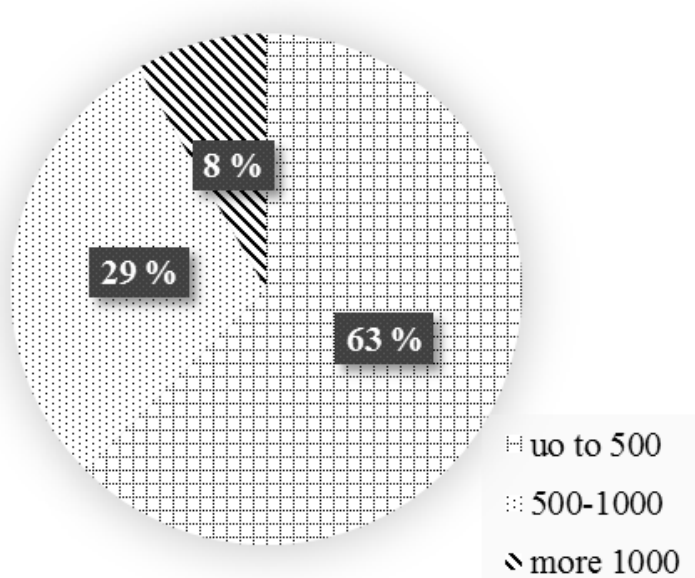

Group II

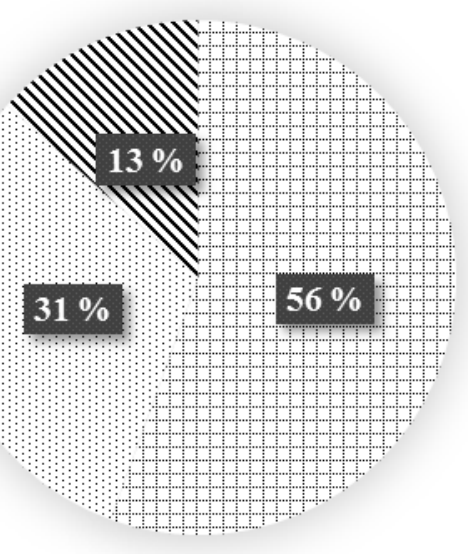

up to 500

$500-1000$

smore 1000

Fig. 1. Number of PVCs episodes per day 
Analyzing the structure of PVCs, it was found that the number of patients with ventricular arrhythmia type 4 and 5 according to Lown was significantly higher in group II compared with group I ( $\mathrm{p}=0.0324)$ (Fig. 2). The presence of ventricular tachycardia was recorded in 3 patients of group I and 5 patients of group II.

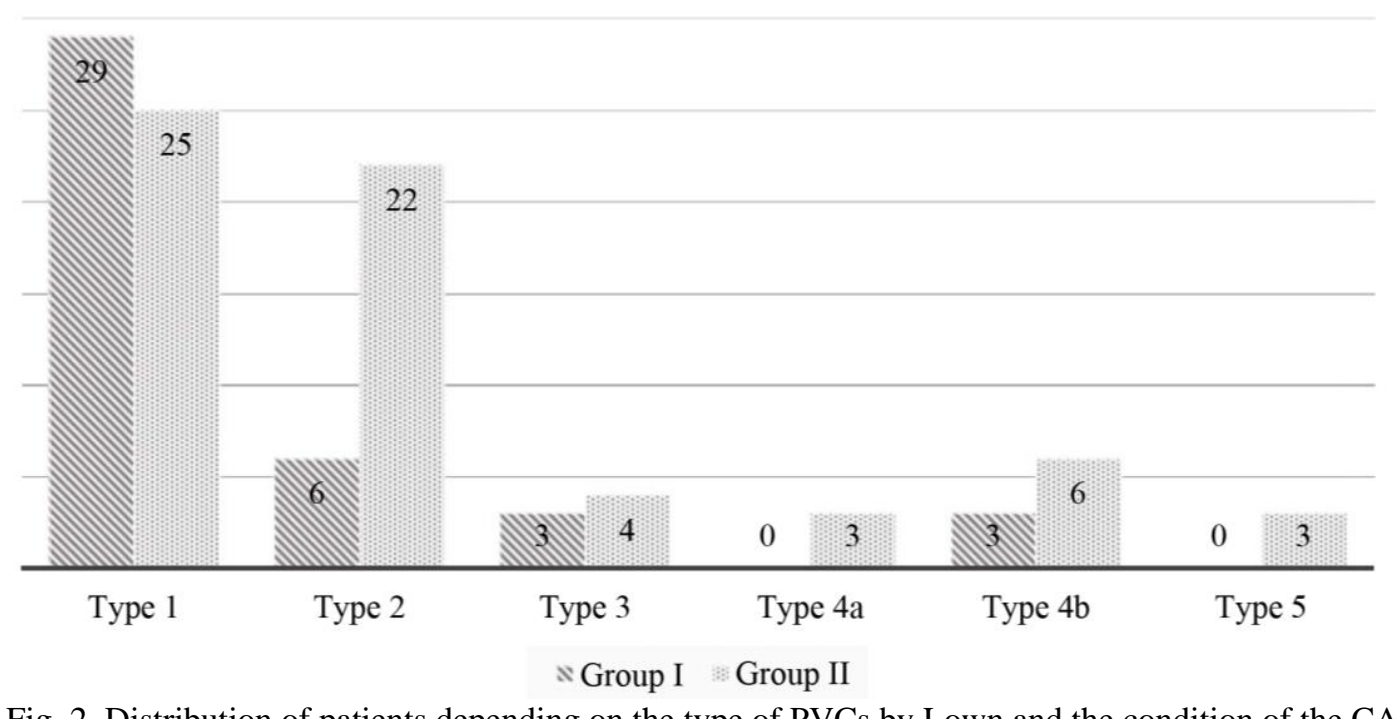

Fig. 2. Distribution of patients depending on the type of PVCs by Lown and the condition of the CA

\section{Discussion}

It is known that the basis of arrhythmia in coronary heart disease is heterogeneity of the myocardium, in the presence of a healthy myocardium, as well as ischemic and/or fibrous areas of the myocardium. A review by P. Harris and other authors showed that there is a direct relationship between the degree of lesion of the CA and the occurrence of ventricular arrhythmias [11, 12]. According to the analysis, arrhythmia was found in most patients with stenotic atherosclerosis $(86.5 \%)$ and in patients with INOCA $(92.3 \%)$. However, after analyzing the structure of arrhythmias, we found that high-grade PVCs (type 4 and above) according to Lown, which are threatening and considered a predictor of sudden death, were more common in patients with coronary heart disease and obstructive atherosclerosis $(23.07 \%)$, compared with INOCA $(5.6 \%)$. These results are consistent with the literature data, with previous reports of similar indicators of PVCs as a consequence of myocardial ischemia in patients with INOCA and patients with obstructive atherosclerosis $[13,14]$. The proportion of patients who experienced atrial fibrillation, left and right bundle branch block did not differ statistically in both groups [15]. In the INOCA group, the duration of episodes of myocardial ischemia was significantly longer compared with patients with stenotic atherosclerosis, which may be associated with a heterogeneous mechanism of occurrence: microvascular and vasospastic ischemia, as confirmed by conducted studies of other authors [16, 17].

Study limitations. Restrictions due to the involvement of small sample of patients.

Prospects for future research. It would be interesting to examine the data from the results of Holter monitoring and to establish key markers of discrepancy in the development of coronary heart disease in a larger cohort of patients, which will provide reliable data. It is important to evaluate the effect of therapy on the duration of ischemia in patients with non-obstructive CAD.

\section{Conclusions}

1. There were no significant differences in group I in the development of myocardial episodes of ischemia compared with patients in group II according to Holter monitoring depending on the lesion of the coronary arteries $(\mathrm{p}=0.420)$.

2. Despite the fact that there is a tendency to reduction of myocardial episodes of ischemia per day in patients in group I than in group II. In the group I in patient with non-obstructive CAD the duration of ischemia is significantly longer than in the group II in patients with obstructive atherosclerosis $(\mathrm{p}=0.042)$.

3. Cardiac arrhythmias according to the results of Holter monitoring were observed in both groups in patients with coronary heart disease with stenotic atherosclerosis and in patients with INOCA, but their structure was slightly different. According to Lown ventricular arrhythmia was statistically significantly more severe in patient with obstructive CAD (group II) compared with patient with non-obstructive CAD group I $(\mathrm{p}=0.0324)$

\section{Conflict of interests}

The authors have no conflict of interests to declare.

\section{Financing \\ None}

\section{Acknowledgments}

We express our gratitude to the patients who took part in the study, as well as the specialists who contributed to the investigation. 


\section{References}

1. Zharinova, O., Ivaniva, Yu., Kutsia, V. (Eds.) (2021). Funktsionalna diahnostyka. Kyiv: Chetverta khvylia, 784.

2. Verna, E., Ghiringhelli, S., Provasoli, S., Scotti, S., Salerno-Uriarte, J. (2018). Epicardial and microvascular coronary vasomotor dysfunction and its relation to myocardial ischemic burden in patients with non-obstructive coronary artery disease. Journal of Nuclear Cardiology, 25 (5), 1760-1769. doi: http://doi.org/10.1007/s12350-017-0871-6

3. Zharinov, O. Y., Kuts, V. O., Tkhor, N. V. (2006). Navantazhuvalni proby v kardiolohii. Kyiv: Medytsyna svitu, 90.

4. Taha, T. (2016). Can early 24 hours Holter monitoring predict obstructive coronary artery lesions in patients with low risk acute coronary syndrome? Journal of the Saudi Heart Association, 28 (3), 207. doi: http://doi.org/10.1016/j.jsha.2016.04.049

5. Ganiga Sanjeeva, N. C., Shetty, R. K., Agarwal, S. (2015). An atypical case of vasospastic angina: demonstrating the usefulness of Holter monitoring. BMJ Case Reports. doi: http://doi.org/10.1136/bcr-2015-210939

6. Araki, H., Koiwaya, Y., Nakagaki, O., Nakamura, M. (1983). Diurnal distribution of ST-segment elevation and related arrhythmias in patients with variant angina: a study by ambulatory ECG monitoring. Circulation, 67 (5), 995-1000. doi: http://doi.org/10.1161/01.cir.67.5.995

7. Knuuti, J., Wijns, W., Saraste, A., Capodanno, D., Barbato, E., Funck-Brentano, C. et. al. (2019). 2019 ESC Guidelines for the diagnosis and management of chronic coronary syndromes. European Heart Journal, 41 (3), 407-477. doi: http://doi.org/10.1093/eurheartj/ehz425

8. Kunadian, V., Chieffo, A., Camici, P. G., Berry, C., Escaned, J., Maas, A. H. E. M. et. al. (2021). An EAPCI Expert Consensus Document on Ischaemia with Non-Obstructive Coronary Arteries in Collaboration with European Society of Cardiology Working Group on Coronary Pathophysiology \& Microcirculation Endorsed by Coronary Vasomotor Disorders International Study Group. EuroIntervention, 16 (13), 1049-1069. doi: http://doi.org/10.4244/eijy20m07_01

9. Austen, W., Edwards, J., Frye, R., Gensini, G., Gott, V., Griffith, L. et. al. (1975). A reporting system on patients evaluated for coronary artery disease. Report of the Ad Hoc Committee for Grading of Coronary Artery Disease, Council on Cardiovascular Surgery, American Heart Association. Circulation, 51 (4), 5-40. doi: http://doi.org/10.1161/01.cir.51.4.5

10. Harris, P., Stein, P., Fung, G., Drew, B. (2014). Heart rate variability measured early in patients with evolving acute coronary syndrome and 1-year outcomes of rehospitalization and mortality. Vascular Health and Risk Management, 10, 451-464. doi: http://doi.org/10.2147/vhrm.s57524

11. Ryngach, E. A., Treshkur, T. V., Tatarinova, A. A., Shlyakhto, E. V. (2017). Algorithm for the management of patients with stable coronary artery disease and high-grade ventricular arrhythmias. Terapevticheskii Arkhiv, 89 (1), 94-102. doi: http://doi.org/10.17116/ terarkh201789194-102

12. Ledakowicz-Polak, A, Ptaszyński, P, Polak, Ł, Zielińska, M. (2009). Prinzmetal's variant angina associated with severe heart rhythm disturbances and syncope: a therapeutic dilemma. Cardiology Journal, 16 (3), 269-272.

13. Pascale, P., Schlaepfer, J., Oddo, M., Schaller, M.-D., Vogt, P., Fromer, M. (2009). Ventricular arrhythmia in coronary artery disease: limits of a risk stratification strategy based on the ejection fraction alone and impact of infarct localization. Europace, 11 (12), 1639-1646. doi: http://doi.org/10.1093/europace/eup314

14. Bière, L., Niro, M., Pouliquen, H., Gourraud, J.-B., Prunier, F., Furber, A., Probst, V. (2017). Risk of ventricular arrhythmia in patients with myocardial infarction and non-obstructive coronary arteries and normal ejection fraction. World Journal of Cardiology, 9 (3), 268-276. doi: http://doi.org/10.4330/wjc.v9.i3.268

15. Ganiga Sanjeeva, N. C., Shetty, R. K., Agarwal, S. (2015). An atypical case of vasospastic angina: demonstrating the usefulness of Holter monitoring. BMJ Case Reports. doi: http://doi.org/10.1136/bcr-2015-210939

16. Myerburg, R. J., Kessler, K. M., Mallon, S. M., Cox, M. M., deMarchena, E., Interian, A., Castellanos, A. (1992). LifeThreatening Ventricular Arrhythmias in Patients with Silent Myocardial Ischemia Due to Coronary Artery Spasm. New England Journal of Medicine, 326 (22), 1451-1455. doi: http://doi.org/10.1056/nejm199205283262202

17. Brainin, P., Frestad, D., Prescott, E. (2018). The prognostic value of coronary endothelial and microvascular dysfunction in subjects with normal or non-obstructive coronary artery disease: A systematic review and meta-analysis. International Journal of Cardiology, 254, 1-9. doi: http://doi.org/10.1016/j.ijcard.2017.10.052

Received date 10.03.2021

Accepted date 22.04.2021

Published date 31.05.2021

Tetiana Pylova, Postgraduate Student, Department of Cardiology and Functional Diagnostics, Kharkiv Medical Academy of Postgraduate Education, Amosova str., 58, Kharkiv, Ukraine, 61176

E-mail: pylovatanya@gmail.com 